\title{
Analysis on Application of Traditional Chinese Opera Costume Elements in Contemporary Costume Design
}

\author{
Juan Luo \\ Department of Art and Design, College of Fine Arts, China West Normal University, Nanchong \\ Sichuan, 637001, China
}

Key words: Tradition, Opera costume element, Contemporary, Costume design, Application.

\begin{abstract}
Traditional Chinese opera culture has rich connotations. In the long-time development process of traditional opera culture, costume culture in opera culture has developed and different costume cultural elements have emerged, which have not only enriched opera culture, but also produced positive influence on costume design work. This paper conducts appropriate study on the creation of opera elements in contemporary costume design process on the basis of analysis on the application of traditional opera costume elements in contemporary costume design and expects to form clearer understandings of contemporary costume design and provide reference for the development of contemporary costume design.
\end{abstract}

\section{Introduction}

Traditional costume culture has formed profound cultural accumulation through long-time development. It is also called as "history on body". With the improvement of material standard of living of the public and constant pursuit for spiritual and cultural life in the contemporary society, ideological connotation and main function of costume have changed to a certain extent. It not only meets the demand of people for covering and warming the body, but also manifests the pursuit of people for beauty and fashion. In-depth analysis and interpretation of costume culture can find aesthetic taste reflected by different life habits and customs and then form explicit understandings of different cultural mentality and national concept. Opera costume culture is an important and special constituent part in traditional costume culture, which has extremely strong sense of beauty and artistic conception and gradually develops into the main thought and inspiration source of modern costume design work.

\section{Wide application of traditional Chinese opera costume elements in contemporary costume design}

Traditional Chinese opera costume elements have produced profound influence on contemporary costume design in the development process. Contemporary costume designers attempt to integrate traditional opera costume elements into contemporary costume design from multiple perspectives on the basis of systematic analysis on traditional opera costume elements. Contemporary costume design is provided with brand-new aesthetic connotations. The overall design thought has changed to a certain extent, which highlights national and cultural character and has great value of research.

\section{Application in modeling}

In costume design work, reasonable modeling has decisive influence on the overall image to be presented by costume design and can fully reflect the basic style of modern costume design. Costume color, pattern and basic style generally have certain relation with costume modeling. Therefore, attention should be first paid to the design in modeling in the process of costume design. 
In terms of costume modeling design, outline has decisive influence on costume modeling. Outline is in essence the external contour line of costume and can directly reflect the overall modeling feature of costume. People can produce corresponding visual impression by viewing the overall outline in the process of appreciating costume design. Costume features can be further manifested. According to the analysis on outline modeling in the process of costume design, it has certain consistency from the perspective of letter type and sketch. The basic shape of human body is regarded as the basis no matter how costume outline changes. Systematic study on costume outline finds that it has multiple forms such as $\mathrm{H}$ and A types. $\mathrm{H}$ type can also be called as barrel type which often pursue for loose, smooth and natural features in the design process and is manifested in neutral costume design. In traditional Chinese opera costume culture, boa, short embroidered cape and plait generally belong to $\mathrm{H}$ type. Outline design elements in traditional Chinese opera costume have produced certain influence on Paris women's dress and Southeast Asian costume. It absorbs design elements from $\mathrm{H}$-type gown modeling in traditional opera costume and enriches design modeling. $\mathrm{X}$ type is another important type in modern costume design, also called as sand clock type. It is a design thought put forward according to basic outline of body of females. With waist as the most important design manifestation, it can present the softness and beauty of females more directly. According to analysis on X-type costume design, contemporary costume works designed with $\mathrm{X}$ type can often present the softness and romance of females more perfectly. It is widely applied in female costume. A-type costume outline can also be called as pyramid type, which can generally present strong dynamic features and is widely applied in dress and wind coat design. T-type costume design can manifest obvious inverted triangular features and has certain similarity to men's body type in the manifestation of overall outline. In opera costume design process, the design of armor often uses T-type design thought and expects to fully manifest the manliness and free nature of men ${ }^{[1]}$.O-type costume design is applied in casual wear. It is mainly applied for costume shoulder, collar and trousers. Cloak design in traditional opera costume generally uses O-type design thought.

In contemporary costume design system, the adjustment of costume design outline often regards human body shape as an important basis. Style is designed and adjusted on the basis of keeping basis outline shape, thus producing different visual effect ${ }^{[2]}$.Collar type design is basic work in costume design process, which has clear division in traditional Chinese costume design, including front opening, round collar and stand collar. Collar type design concept in opera costume design is integrated into contemporary costume design. Exaggerated three-dimensional embroidered collar is a reference and adjustment of collar design in opera costume. To manifest a personalized design style in design, shoulder line processing is an important content for designers. With the adjustment of shoulder line, the overall costume style will change correspondingly. In addition, changes and adjustment that can be manifested in the design process of waist are richer in design practice. The integration of design thought in traditional opera costume in contemporary costume design can manifest different design styles and nationalized artistic conception in modeling design. For example, wide sleeve in traditional Chinese opera costume is wide and long. Its application in modern costume design can manifest certain traditional design style, reflect the formal beauty of costume design and provide contemporary costume design with deeper ideological connotations.

\section{Application in color element}

In opera costume design and modern costume design, color plays a vital role, implies profound cultural connotations and produces vital influence on the development of costume design work. Therefore, designers positively use the application thought of color in traditional Chinese opera costume design and manifest certain artistic charm of national costume design in contemporary costume design work ${ }^{[3]}$.For example, in terms of contemporary costume design, some designers integrate representative Chinese red into fashionable dress design and reflect certain opera design style. Red dress edge of Leonard in 2008 used red color of opera style and presented certain Chinese style. In traditional Chinese opera culture, green is a color that can make people relax both in body and mind. Deep green is often used in opera costume to present manliness and loyalty of veterans. 
Yellow is the symbol of power and luxury and has obvious representativeness. To integrate coloring thought in opera costume design into contemporary costume design, golden yellow is often used for separation, showing luxury and dignity. Attention should be paid that, to present strong artistic impact with reasonable use of color, contemporary costume designers pay attention to not only cultural connotations of color but also color matching and harmony while using opera costume elements for design and expect to integrate opera elements better with the adjustment of color distribution area and matching lightness and show certain beauty of decoration and color matching.

\section{Application in fabric element}

In contemporary costume design, fabric selection and combination are also influenced by traditional opera costume culture. With different costume fabrics, people have different experience in the process of appreciation and touching. Reasonable use and combination of fabrics can make costume design manifest an overall beauty of artistic. In traditional opera costume design, there are generally soft and hard fabrics ${ }^{[4]}$. They are respectively used to show the softness and manliness of characters. The use of large satin fabric can not only show manliness of men, but also manifest the beauty of softness of women. Multiple elements in opera costume are widely applied in modern costume design process. As the basis of costume design innovation, fabric creates good conditions for reasonable adjustment and innovation of costume design by designers. Designers further adjust fabric design on the basis of integrating opera design thought and can achieve unexpected artistic effect. For example, appropriate color decoration and pattern processing of fabric through the integration of opera elements can effectively change the original feature of fabric and make it present different visual effect and tactile effect. Fabric design with destructive method such as drawing and hollowing can realize change of fabric structural features. Presentation mode of costume design can be different. The absorption of certain opera costume elements in fabric design brings new vitality and vigor to contemporary costume design.

\section{Creative manifestation of opera costume elements in contemporary costume design}

Opera costume elements mostly manifest the inheritance of traditional Chinese cultural thought in the development process. In recent years, as the development of China and traditional Chinese cultural elements arouse wide attention of the world, Chinese costume designers have started to draw inspiration from opera costume design in the process of exploring contemporary costume design. To highlight era character and innovation, they no longer use cultural elements in opera costume design for reference simply; instead, they make innovative application on the basis of integrating modernity and expect to highlight features of contemporary costume design and show unique cultural charm of contemporary costume design.

For example, in the design process of Chinese wedding dress, contemporary costume designers absorb and use costume elements in traditional Chinese opera culture appropriately, integrate design thought of western wedding dress for reasonable innovation, form characteristic cultural connotations of Chinese wedding dress and manifest unique artistic charm. In terms of the selection of Chinese wedding dress pattern, designers are often inclined to mass phoenix pattern or flying phoenix pattern under the influence of traditional opera costume culture and constitute "phoenix" series of Chinese wedding dress ${ }^{[5]}$. Meanwhile, designers also strengthen the introduction and creative application of opera costume elements in the design process of dinner jacket. For example, the creative application of dragon pattern, phoenix pattern or water wave and cloud pattern in short dinner jacket can enrich costume fabric and present novelty and artistic features. In Chinese long formal dress, designers integrate design thought of cloud shoulder in opera costume element on the basis of systematic analysis and form unique design style in combination with contemporary costume design elements, which can further manifest the soft line of females' shoulder. In addition, during creative application, designers explore the integration and extraction of different opera costume elements, select points adapted to modern design thought, further enrich design thought and highlight unique artistic connotations of contemporary Chinese costume design. According to analysis from the perspective of 
color matching of traditional opera costume, it can produce certain influence on contemporary costume design. Designers apply common red and golden colors in opera costume design to contemporary evening dress design, which presents the profound costume culture of China to a certain extent and effectively promotes organic integration between Chinese opera costume elements and contemporary costume design thought. Systematic analysis on contemporary costume design finds that creative application of opera costume elements is manifested in many aspects such as underwear design, gymnastics and sports wear design. It not only strengthens ornamental value and artistic feature of costume, but also allows more people to understand Chinese costume culture, effectively promotes good development of Chinese contemporary costume culture in the new period, achieves corresponding development effect and obtains wide recognition of the public. On this basis, in order to achieve good design effect in contemporary costume design, designers should pay attention to make constant explorations in the integration of contemporary elements with opera costume elements and attempt to apply it to costume design work creatively, highlight the value of costume design, effectively promote new development of Chinese contemporary costume design culture in the new period and gradually accelerate internationalized development process of Chinese costume design work.

\section{Conclusion}

Chinese traditional opera costume elements have rich form and profound cultural connotations. Reasonable application of traditional opera costume elements in contemporary costume design process can further improve the cultural and artistic character of contemporary costume design and manifest unique charm of traditional Chinese opera costume elements. Therefore, designers should positively explore the integration of traditional opera costume elements into modern costume design, enrich contemporary costume design and promote better development of Chinese contemporary costume design in design practice. Meanwhile, blind use for reference should not be done in the process of integration of traditional costume elements into contemporary costume design activities. It is also required to integrate contemporary design concept for innovating traditional opera costume elements, integrate it into contemporary costume design creatively and promote better development of contemporary costume design.

\section{Acknowledgement}

Fund program: Study on Opera Costume within the Scope of Local Culture Promotion - Take Gao'an Tea-Leaf Picking Opera for Example.

\section{References}

[1] Chen Zhihua. Application of Traditional Chinese Opera Costume Elements in Contemporary Costume Design, Shaanxi Normal University, 2014.

[2] Liu Yang. Study on Application of Chinese Opera Elements in Costume Performance, Dalian Polytechnic University, 2015.

[3] Zhang Xueyun. Analysis on Traditional Costume Elements and Study on Its Application in Game Role Costume Design, Theatrical Family, 2016(12):157-160.

[4] Kang Juan. Brief Discussions on Application of Chinese Opera Elements in Modern Costume Design, Art Science and Technology, 2012(5):116-116.

[5] Li Shumin. Application of Opera Costume Elements in Contemporary Creative Costume Design, Humanity World, 2016(2):84-86. 